\title{
La recepción de la democracia ateniense en la filosofía política de Antoni Domènech: el sorteo y su trasfondo ético y antropológico*
}

\author{
The reception of Athenian democracy in the political \\ philosophy of Antoni Domènech: The draw and its ethical and \\ anthropological background
}

FRANCISCO VÁZQUEZ GARCÍA**

\begin{abstract}
Resumen: En este artículo se analiza la recepción de la institución ateniense del sorteo en la filosofía política de Antoni Domènech (n. 1952). Tomando como referencia principal el libro De la ética a la política (1989), se examina la perspectiva de su autor sobre el trasfondo ético y antropológico del republicanismo antiguo, a partir de los conceptos de "razón erótica" y "tangente ática". Por otra parte, utilizando la metodología de la sociología de la filosofía, se localiza su intervención en el campo filosófico español de la década de 1980. Por último, se estudia el modo en que la referencia a la filosofía antigua le sirve a Domènech para pronunciarse sobre el debate coetáneo en torno a la crisis de la razón moderna.

Palabras clave: sorteo, democracia, Domènech, filosofía española, crisis de la razón, filosofía política, republicanismo.
\end{abstract}

\begin{abstract}
In this paper we analyze the reception of the Athenian lottery institution in the political philosophy of Antoni Domènech (b. 1952 ). On the one hand, taking the book De la ética a la política (1989) as our main reference, we focus on the author's view about the ethical and anthropological background of ancient republicanism. Domènech perspective is based on the concepts of "razón erótica" and "tangente ática". On the other hand, using the methodology of the sociology of philosophy, its intervention is located in the Spanish philosophical field of the 1980s. Finally we explore the way ancient philosophy serves Domènech to take sides in the contemporary debate on the crisis of modern reason.

Keywords: lottery, democracy, Domènech, Spanish philosophy, crisis of reason, political philosophy, republicanism.
\end{abstract}

Fecha de recepción: 27/07/2016. Fecha de aceptación: 10/01/2017.

* El presente texto se publica en el marco del proyecto denominado "La recepción de la filosofía grecorromana en la filosofía y las ciencias humanas en Francia y España desde 1980 hasta la actualidad”, financiado por el Programa Estatal del Ministerio de Economía y Competitividad, Convocatoria de 2014, I+D: FFI2014-53792-R.

** Francisco Vázquez García. Catedrático de Filosofía por la Universidad de Cádiz. Especialista en filosofía contemporánea española y francesa y en historia cultural de la sexualidad. Sobre sociología de la filosofía ha publicado La filosofía española. Herederos y pretendientes. Una lectura sociológica (1963-1990), Madrid, Abada, 2009 y Hijos de Dionisos. Sociogénesis de una vanguardia nietzscheana (1968-1985), Madrid, Biblioteca Nueva, 2013. Contacto: francisco.vazquez@uca.es 


\section{Introducción}

El sorteo, vinculado a la rotación de cargos y a la rendición de cuentas, y el salario, que permitía la participación política de los ciudadanos pobres, fueron los diseños institucionales nucleares de la democracia ateniense desde su instauración, con la revolución de Efialtes en el 461 a. de C. (Manin 2015, 19-58).

Antoni Domènech, discípulo de Manuel Sacristán y uno de los más avezados estudiosos de nuestro país en el ámbito de la filosofía moral y política, desarrolló en sus dos obras principales, De la ética a la política (1989) y El eclipse de la fraternidad (2004), una reflexión a la vez histórica y normativa, donde la democracia ateniense ocupaba un lugar fundamental. El primero de estos trabajos, como trataremos de mostrar, ponía de relieve la conexión entre el diseño institucional del sorteo y la prevalencia de lo que Domènech denomina "razón erótica" en la cultura moral de la Antigüedad. El segundo, por otro lado, localizaba en el dispositivo del salario la condición que hacía posible universalizar la libertad republicana, asentando la democracia en el valor de la fraternidad.

A través de esta meditación acerca de la democracia ateniense, sobre la base material y social que la sustentaba y sobre los conceptos que articulaban su tradición, Domènech tomaba posición en los debates filosófico-políticos del mundo contemporáneo. Se situaba así en el espacio de atención de la controversia actual, tanto a escala internacional como en el campo filosófico español. Enmarcado en una determinada trayectoria dentro de este universo, dotado de unos recursos simbólicos e institucionales específicos, Domènech elaboró una respuesta original a partir del conjunto de alternativas teóricas que encontró.

Nuestro objetivo, valiéndonos del instrumental analítico que proporciona la sociología de la filosofía, consiste en reconstruir la aparición de las intervenciones de Domènech, y más concretamente sus interpretaciones de la democracia ateniense, dentro del espacio coetáneo de la filosofía española. Se trata en cierto modo de desenterrar el campo de batalla donde se inscribieron sus estrategias y tomas de posición.

No hay que olvidar aquí la distancia que media entre los dos trabajos mencionados. De la ética a la política, publicada como libro en 1989, fue presentada como tesis doctoral dos años antes, y su elaboración tuvo lugar principalmente entre 1982 y 1985, en un proyecto financiado por el Deustcher Akademischer Austauschdienst, desarrollado en Berlín (Domènech 1989, 30). Por otro lado, aunque el impulso inicial de El eclipse de la fraternidad se remonta a comienzos de la década de 1990, el texto, inicialmente concebido como "introducción histórica" de un ensayo de corte sistemático, sólo cobró forma en el tránsito al siglo XXI. (López Arnal, 2005, 281-314 y 281-282)

La coyuntura política y filosófica no era la misma en cada caso. En la circunstancia de la tesis doctoral, el centro de atención del debate filosófico lo ocupaba el problema de la razón moderna y de su eventual crisis. En el estudio acerca de la fraternidad la discusión se ha hecho más especializada y concierne al asunto del republicanismo. En el primer caso el encuadre político viene dado por la vigencia de la Guerra Fría y de la carrera armamentística, cuando las formas de gobierno neoliberal empezaban a despegar. En el segundo, el escenario venía dado por el apogeo del neoliberalismo, dentro de un nuevo orden internacional donde cobraba fuerza el movimiento altermundista. 
Tampoco son idénticas las claves de aproximación a la democracia ateniense y a la cultura político-moral del mundo antiguo. En De la ética a la política interesaba sobre todo el concepto de "razón erótica"; desde esta noción se afronta la discusión sobre la democracia ateniense y se alude a la cuestión del sorteo. En El eclipse de la fraternidad, el eje de preocupación lo constituye la extensión universal de la libertad republicana y la referencia al salario de los pobres como mecanismo que la hace posible.

En el presente artículo nos concentraremos en la primera cuestión, dejando para un trabajo posterior el examen de la segunda.

\section{La trayectoria de Domènech y el despegue de la filosofía moral y política en la Tran- sición española}

Cuando Antoni Domènech, hacia 1982, se trasladó a Berlín para dar forma a su tesis doctoral, tenía ya tras de sí una prolongada y reconocida trayectoria intelectual en el campo filosófico español. Desde mediados de la década de 1970, era considerado el miembro quizás más destacado de la segunda generación de los discípulos de Manuel Sacristán. Si la primera encuadraba a profesores como Juan Ramón Capella, Francisco Fernández Buey y Jacobo Muñoz, en la segunda descollaba Antoni Domènech. Este, junto a Muñoz y a Gerard Vilar constituyó el denominado Col.lectiu Critica, cuya puesta de largo tuvo lugar en lo que entonces era considerado el happening filosófico anual por excelencia: los Congresos de Filósofos Jóvenes. La secretaría organizadora del celebrado en Cádiz en 1976, titulado "Filosofía e Historia", recayó precisamente en el mencionado Col.lectiu, destacando las ponencias presentadas por Antoni Domènech y Gerard Vilar. La edición del año siguiente, celebrada en Barcelona ("Filosofía y Enseñanza"), sirvió para dar a conocer el grupo a escala nacional (Vázquez, 2009, 336-385 y Moreno Pestaña, 2015).

Domènech, junto a sus compañeros, se involucró en tres grandes debates teóricos del momento. En primer lugar, la controversia sobre la lectura althusseriana de Marx, desacreditada por los sacristanianos, que subrayaron la debilidad epistemológica de los planteamientos de Althusser, en contraste con la solidez de los análisis de la estructura lógica de El Capital, propuestos por el checo Jindrich Zeleny. En segundo lugar, la discusión del momento entre tradición analítica y tradición dialéctica. En este caso, los discípulos de Sacristán atentos, no sólo a la metodología de la ciencia de inspiración analítica, sino al propio desarrollo de las ciencias sociales en sus técnicas empíricas de investigación, promovieron una revisión crítica de esta tradición, depurándola de su sesgo academicista -cuestionando por ejemplo la disociación entre contexto de descubrimiento y contexto de investigación, y conciliándola con un marxismo entendido como saber de "totalidades concretas" y animado por una intención emancipatoria. Por último, el grupo se pronunció contra una concepción sustantiva y universitaria de la filosofía, como la que podía representar entonces la lectura de Marx propuesta por Gustavo Bueno y sus seguidores, concretada en el sistema del materialismo filosófico. Optaban en cambio por identificar la filosofía con una ciencia social crítica, familiarizada con los procedimientos investigación empírica pero guiada por el propósito emancipatorio de transformar el mundo (Vázquez, 2009, 360-365).

En esa escuela que compuso durante más de una década el colectivo de Sacristán, se formaron las disposiciones intelectuales de Domènech. Este estaba dotado de un abun- 
dante capital político de signo militante, fraguado dentro del PSUC en las luchas del final del antifranquismo y los primeros años de la Transición. Por otra parte, procediendo de una burguesía catalana ilustrada y viajada, de industriales medios, contaba con recursos culturales muy importantes, especialmente de índole histórica, idiomática y literaria ${ }^{1}$. Por otra parte, la composición de su capital intelectual, como correspondía a un seguidor de Sacristán, era característicamente híbrida. El conocimiento profundo de la tradición de la historia de la filosofía -aquí fue también estimulante el contacto con Wolfgang Harich, se completaba con una familiaridad inusual, incluso dentro del círculo sacristaniano, con las herramientas de la ciencia social empírica. Dominio de la teoría económica en sus variantes clásica y neoclásica, conocimiento del instrumental lógico-matemático más exigente (teoría de juegos, teoría de la optimización, teoría de la decisión racional) e incursión en el ámbito de las neurociencias y de la psicología (en particular la escuela psiquiátrica de Palo Alto).

Hasta la fundación del Instituto de Filosofía del CSIC en enero de 1986, que reemplazó al viejo Instituto Luis Vives, la filosofía moral y política ocupaba una posición secundaria en el currículo de las Facultades de filosofía. La Ética, encuadrada durante mucho tiempo en estos centros junto a la Sociología, era considerada una disciplina de rango menor dentro de la jerarquía de materias filosóficas, en contraste con la Metafísica o la Historia de la Filosofía. Por otro lado, la reflexión sobre los fundamentos de la política había sido un asunto monopolizado tradicionalmente por los filósofos del derecho, bien en las Facultades jurídicas, bien en el Instituto de Estudios Políticos, fundado y promovido durante décadas por intelectuales próximos a Falange.

Contando con el apoyo del Ministerio de Educación del PSOE, Reyes Mate vio coronada con éxito su mediación (Mate, 2012, 21-25). Su propósito era poner en marcha un centro del CSIC dedicado a las ciencias de las religiones, pero tras descartar que el nuevo establecimiento se convirtiera en una suerte de versión "nacionalizada" del Instituto Fe y Secularidad impulsado por los jesuitas, llegó a un acuerdo con Javier Muguerza y Fernando Quesada. El segundo eje del Instituto sería la investigación en el ámbito de la filosofía moral y política. Este campo, gracias en parte al empeño de Muguerza, había alcanzado en 1983, dentro de la Ley de Reforma Universitaria, el rango de área de conocimiento -aunque inicialmente englobado como "filosofía del derecho, moral y política". De este modo, lo que en otro lugar hemos denominado "nódulo de Aranguren-Muguerza" lograba (Vázquez, 2009, 157-219), no sólo la preeminencia intelectual en la esfera de la filosofía española, sino un emplazamiento institucional de privilegio, liberado de las herencias recibidas y los constreñimientos propios de los departamentos universitarios. Javier Muguerza ejerció como primer director del Instituto, mientras que Reyes Mate lo hacía como primer presidente del Patronato. El órgano editorial del establecimiento lo constituía la revista Isegoría, cuyo primer número vio la luz en 1990. Pues bien, desde el primer momento, la tesis doctoral de Domènech fue bien acogida en este espacio que entonces se abría. Javier Muguerza, que siempre había manifestado su aprecio intelectual por Sacristán y su círculo, fue quien presidió en 1987 el tribunal que juzgó el trabajo de Domènech. Este fue sometido a discusión en un seminario del Instituto, organizado por

1 Se pueden encontrar alusiones a los orígenes familiares en Domènech 2004, 24, 159 y 404. 
Francisco Álvarez, Julia García de la Maza, Ana Lizón y José María González García (Domènech, 1989, 31). Domènech se convirtió, desde entonces, en un asiduo ponente de los seminarios organizados por el Instituto. Muchas de sus publicaciones más destacadas son contribuciones realizadas en el marco de proyectos y seminarios promovidos por este centro, desde la Enciclopedia Iberoamericana de Filosofía, dirigida por Reyes Mate (Domènech, 2005), hasta diversos volúmenes colectivos editados con fondos del Instituto (Domènech, 1991 y 1995) ha colaborado también en la revista Isegoría (Domènech, 1993 y 1998) ${ }^{2}$ y su último libro, El eclipse de la fraternidad, fue objeto de un monográfico de la Revista Internacional de Filosofía Política ${ }^{3}$.

Por otro lado, los dos libros hasta la fecha publicados por Antoni Domènech, vieron la luz en la editorial Crítica, un sello fundado en 1976 por Gonzalo Pontón, ligado a Sacristán desde los tiempos de Ariel. Pero además, la tesis doctoral de Domènech se editó en una colección dirigida por Victoria Camps, muy vinculada al grupo de Javier Muguerza y admiradora, desde su juventud, de Manuel Sacristán.

Por lo tanto, la confección y circulación de De la ética a la política sólo puede entenderse por referencia a esta red intelectual que funcionó a la vez como ámbito de resonancia de la obra. Ahora bien, ¿qué recepción de la democracia ateniense y de la figura del sorteo puede encontrarse en este libro?; ¿en qué medida esa recepción implicaba un envite original dentro del debate sobre la "crisis de la razón" que ocupaba a los filósofos del "nódulo de Muguerza"? o, dicho de otro modo, ¿de qué modo la discusión sobre la cultura políticomoral de los griegos le servía a Domènech para debatir con sus coetáneos?

\section{Sorteo y cultura moral en el marco de la polis. La recuperación de la razón erótica}

Antoni Domènech no es un especialista en historia antigua ni en filosofía griega, y las referencias de De la ética a la política a la democracia plebeya ateniense iniciada con la revolución de Efialtes, y aún más a la institución del sorteo son muy puntuales. No obstante, la lectura decisiva para los análisis de la democracia ateniense contenidos en aquel libro la constituyen los estudios del clasicista alemán Arthur Rosenberg (1889-1943), especialmente Demokratie und Klassenkampf in Altertum (1921) (Rosenberg, 2006). Esta obra, un texto redactado como manual para la Universidad Popular de Berlín, donde su autor era docente, es calificada por Domènech como un ensayo "breve e insuperado"4. Rosenberg, discípulo del gran historiador reaccionario Eduard Meyer, experimentó un vuelco ideológico después de 1918, transitando del nacionalismo conservador al KPD, llegando a ocupar en 1924 un puesto de diputado en el Reichstag. Unos años después se distanció del comunismo, aproximándose al socialismo democrático. En 1933, tras la conquista del poder por los nazis, huyó a Suiza, siendo después profesor en Gran Bretaña y Estados Unidos, donde falleció en 1943.

2 El artículo de 1993 recoge una intervención realizada en el curso de un Homenaje a Aranguren, celebrado en 1992.

3 Véanse los artículos de Antonio García Santesmases, Javier Peña y Jaime Pastor, además de las respuestas de Antoni Domènech, en Revista Internacional de Filosofía Política, 25 (2005).

4 Domènech $(1989,89)$. Sobre Rosenberg, su posición en la tradición del clasicismo alemán y la génesis del concepto de "democracia burguesa", Domènech (2009). 
La originalidad política e historiográfica de Rosenberg, expuesta en textos como el mencionado Demokratie und Klassenkampf im Altertum (1921), Geschichte des Bolschewismus: Von Marx bis zur Gegenwart (1932), Entstehung und Geschichte der Weimarer Republik (1935) y Demokratie und Sozialismus (1938) (este último es calificado por Domènech como libro "insuperable" -Domènech, 1989, 258-), es su insistencia en cuestionar el supuesto antagonismo entre democracia y comunismo: la democracia es el gobierno de los pobres. Rosenberg recalcó el enraizamiento, palpable ya en el joven Marx, del proyecto socialista en la tradición democrática. Por esta razón se opuso a la política cerradamente obrerista de los partidos de la izquierda alemana, defendiendo en cambio una alianza interclasista que ponía el énfasis en la democratización radical de todas las relaciones sociales.

Esta perspectiva se hace patente en los dos libros de Domènech, que han contribuido a reactivar en España el trabajo de este clasicista bastante olvidado por los historiadores (con la excepción de Luciano Canfora), debido a la vez a su compromiso político y a su independencia de juicio. Rosenberg, que identificaba la lucha de clases en la Antigüedad como un conflicto entre ciudadanos ricos y pobres libres (más que como antagonismo entre señores y esclavos), veía en la democracia plebeya de Efialtes el punto de partida de una tradición continuada por Robespierre, el socialismo de Marx y Engels, la experiencia de la Comuna de París y el leninismo (Rosenberg, 2006, 86).

De la ética a la política alude de pasada a la institución del sorteo cuando se refiere a la revolución del 461 a. de C., liderada por Efialtes. Esta supuso una ruptura con la vieja constitución de Clístenes, haciendo efectiva por primera vez la participación y el protagonismo de los pobres libres (thetes, trabajadores asalariados) en la vida pública, "permitiendo la remuneración de los cargos políticos", combatiendo a la vez, mediante el recurso del sorteo, la monopolización oligárquica de las magistraturas: "la mayoría proletaria de la población se reflejaba en la elección por sorteo y garantizaba automáticamente el gobierno de los desposeídos" 5 .

El propósito de Domènech no es detenerse en el análisis de estos diseños institucionales; lo que le interesa es destacar su rechazo por parte de la tradición filosófica dominante, desde Sócrates a Aristóteles pasando por Platón. Estos autores parecen defender un republicanismo antidemocrático, en la línea de la constitución de Clístenes. Se acepta el sorteo pero se restringe a las élites, pues queda excluida de entrada la asignación de un salario por el desempeño de cargo público.

La segunda alusión al sorteo se encuentra casi al final del libro. En este caso el dispositivo institucional aparece descontextualizado históricamente ${ }^{6}$, pero tiene mucha más importancia para el argumento central defendido por Domènech.

5 Domènech (1989) Cuando Domènech publicó su tesis, todavía no se había editado en inglés (la edición danesa original, en seis volúmenes, vio la luz entre 1977 y 1981) la obra fundamental sobre el sorteo, el estudio de M. H. Hansen (1991), aunque sí los importantes trabajos de Moses I. Finley. Domènech recurre a la relevante monografía de E. Staveley (1972).

6 En este caso, Domènech no está interesado en evocar el procedimiento del sorteo tal como funcionó históricamente en la democracia ateniense. Más bien su interés es formal y normativo; en la línea abierta por Jon Elster (Domènech tradujo al castellano el segundo capítulo de los Solomonic Judgements, donde el filósofo noruego se ocupó del sorteo), lo que le interesa es cómo funcionan los procedimientos azarosos (sorteos, loterías, etc.) en la toma de decisiones colectivas. Véase Domènech (1988, 33-34). 
En el capítulo de conclusiones que cierra De la ética a la política (Domènech, 1989, 353-358), se señala la necesidad de contar con una cultura moral que permita la elección social consciente de la humanidad, amenazada hoy por la crisis de los recursos energéticos y alimenticios, la destrucción de la biosfera, la crisis demográfica y el riesgo de extinción de la especie por guerra nuclear.

Se trataría de promover una cultura moral que convirtiera a la humanidad consciente en dueña de su destino. Pero las ciencias sociales contemporáneas han explorado a fondo las dificultades que bloquean la posibilidad misma de emprender una elección social racional: dificultades de información sobre las preferencias de los individuos en sociedades complejas; problemas de motivación de los sujetos y obstáculos a la hora de obligarlos a actuar de un modo u otro. Domènech se centra especialmente en dilucidar la primera dificultad.

El utilitarismo ha sido la teoría que ha alentado la cultura moral dominante, hasta verse cuestionado por el revival de nuevos sistemas normativos de factura neotrascendental (Rawls, Nozick, Habermas). La exclusión utilitarista de la elección social racional parece quedar confirmada por la célebre paradoja o teorema de imposibilidad, formulado por el Premio Nobel de Economía de 1972, el estadounidense Kenneth Arrow, en su tesis doctoral Social choice and individual values, publicada como libro en 1951. Este teorema establece la imposibilidad de la elección social racional, presuponiendo que la elección social entre dos opciones debe ser independiente. Pero esto, señala Domènech, implica tres condiciones. En primer lugar, que las preferencias no pueden fijarse de manera cardinal sino sólo ordinalmente. En segundo lugar, y aquí aparece de nuevo la institución del sorteo, el teorema excluye el uso de loterías o métodos azarosos en los procesos electorales "al modo de la democracia ateniense" (Domènech, 1989, 356) 7 . Y en tercer lugar, pero esta condición parece obvia e indiscutible, excluye la no independencia de la elección social entre dos opciones.

La institución del sorteo como mecanismo para la adopción de decisiones colectivas aparece por tanto al examinar críticamente el supuesto antropológico -inherente al utilitarismo y al teorema de la imposibilidad de Arrow, de que las preferencias de los electores vienen dadas y son inmodificables en el proceso de toma de decisiones. El sorteo, sugiere Domènech, además de garantizar el carácter anónimo de la elección -evitando la formación de grupos de intereses, obliga a debatir públicamente en el ágora sobre las preferencias políticas de los ciudadanos.

El sorteo, que en la democracia ateniense funcionaba básicamente como un mecanismo para la elección de cargos (de los representantes de la Boulé, de los tribunales y las magistraturas propiamente políticas, que no exigían ningún saber especializado), aparece vinculado por Domènech con la toma de decisiones. Su adopción aleatoria en una asamblea significa que su probabilidad depende de la cantidad de individuos que desean esa alternativa: "si 2/3 de los electores prefieren $\mathrm{X}$ a $\mathrm{Y}$, entonces el mecanismo azaroso selecciona $\mathrm{X}$ con probabilidad de $2 / 3$, pero da, al mismo tiempo, a Y la probabilidad de $1 / 3$ ".

7 En esta página y en la siguiente parece sugerirse que en la democracia ateniense se usaba el sorteo para adoptar decisiones. En realidad el método de lotería se empleaba para la asignación de cargos (formar parte de la Boulé, de los tribunales, ocupar las magistraturas que no exigían preferencias profesionales). Véase Manin (2015, 19-58). 
Domènech subraya entonces las ventajas asociadas al diseño institucional del sorteo: a) presupone que las preferencias no vienen dadas sin más; pueden ser alteradas y elegidas por los sujetos; b) exige la deliberación previa a la elección, con objeto de intentar persuadir al oponente; c) obliga a buscar posiciones consensuales, unánimes, con objeto de evitar o minimizar el posible triunfo de las opciones minoritarias.

La adopción del procedimiento aleatorio favorece así la formación de disposiciones políticas a través de la participación y la deliberación, ya que aquéllas no se consideran dadas e inmodificables. Por otro lado presupone la distribución equitativa de los recursos políticos; todos son considerados como capaces de hacer valer sus preferencias en el gobierno de la cosa pública, sin que una minoría de expertos, una élite de sabios o una camarilla de intereses monopolice el poder de decisión. Además, este dispositivo azaroso rompe la lógica agregacionista del utilitarismo ya que en principio abre la puerta al triunfo de la minoría. Pero lo más importante es que el sorteo, al estimular la búsqueda de opciones consensuadas mediante la deliberación, hace posible llegar a una elección social racional.

Aunque el análisis de Domènech pondera las bondades del mecanismo aleatorio en los procesos de elección colectiva, en ningún momento llega a defender abiertamente su reintroducción en el funcionamiento de las democracias modernas. Sugiere en cambio que las sociedades de mercado no parecen compatibles con la generación y distribución de información sobre las preferencias individuales que implica el mecanismo del sorteo, ya que este exige debatir los deseos de los otros y modificarlos. Su referencia al sorteo, más que situarse en un plano propositivo e institucional, se mueve en un ámbito crítico y moral. Le permite establecer los límites éticos, psicológicos y antropológicos del utilitarismo y de los teoremas de Arrow. Estos descansan en el supuesto de que las preferencias no cambian en el curso del proceso electoral. Domènech enlaza así con el argumento general de su libro: las democracias modernas se asientan en el ejercicio de una "razón inerte" que excluye la alteración y la elección racional de los propios deseos. Su persistencia impide siquiera plantearse la posibilidad de una elección social racional, esto es, una ética racional, donde los deseos, como sucede con las creencias en el ámbito cognitivo de la ciencia, puedan ser rectificados y reemplazados. La democracia ática, entendida como "gobierno de los pobres libres", fundada en el sorteo y en el salario de los cargos, presupone en cambio la posibilidad de alterar las preferencias, es decir, el ejercicio de una razón erótica que sería inherente a la ética republicana prevaleciente en el mundo grecorromano.

La democracia ateniense presuponía por tanto la existencia de una cultura moral fundada en la "razón erótica", donde el bien público era inseparable del logro de la virtud privada -lo que Domènech denomina "el juego de la tangente ática" (Domènech, 1989, 77-131), un planteamiento situado en las antípodas del utilitarismo moderno. Pero esa misma razón erótica desplegada por el hombre que se autogobierna y elige sus deseos, el enkratés, es asumible desde un republicanismo no democrático, que restringe la libertad a una minoría. El mecanismo del sorteo, desvinculado en este caso de la institución del salario para los cargos, es perfectamente aceptable desde esta posición, y así sucedía en la polis ateniense antes de la revolución efiáltica. La razón erótica puede incluso preservarse fuera del marco de la polis, vinculada a la aceptación del despotismo imperial, como sucedió en las escuelas filosóficas del periodo helenístico. 
Se ha dicho que esta reconstrucción de la razón erótica vigente en la cultura moral de la Antigüedad griega, constituye una "idealización” del mundo clásico (Mosterín, 1989, $15-16)^{8}$. Pero Domènech no describe la vida real en la polis ateniense y mucho menos presupone que las especulaciones de los filósofos sean el motor de los cambios históricos, argumento que rechaza de plano. Compone un idealtipo -la "razón erótica" plasmada ejemplarmente en el juego de la "tangente ática"- que recoge, resaltados, los rasgos de una tradición moral hoy olvidada. Sus referencias al sorteo y al salario como dimensiones institucionales de la democracia ateniense después de la revolución de Efialtes, inspiradas en buena medida por la lectura de Rosenberg, deben ser tomadas en el mismo sentido. Describen, en condiciones idealtípicas, el funcionamiento de esos mecanismos como posibilitadores de una libertad republicana universalizada.

Por tanto, más que una visión arcádica o idealizada del mundo clásico, lo que se encuentra en De la ética a la política, en el plano metodológico, es un concienzudo intento para evitar las analogías salvajes tan frecuentes en los usos hermenéuticos de la historia de la filosofía9. Con objeto de "urbanizar" el análisis histórico-comparativo, Domènech recurre a la formalización utilizando creativamente la teoría de juegos. Los idealtipos de las distintas configuraciones ético-políticas exploradas (tangente ática, absolutismo, liberalismo, republicanismo liberal, republicanismo absolutista, etc.) aparecen reconstruidos como otros tantos juegos de pérdida y ganancia, referidos a la elección de preferencias. Esto permite, no sólo una ganancia de claridad y rigor en la exposición, sino el despliegue de una interpretación empíricamente controlada gracias a la ejemplificación de coocurrencias históricas altamente improbables, es decir, no triviales (Passeron, 1991, 594-608).

\section{El debate político-moral del mundo clásico y sus reflejos especulares en la contro- versia actual}

La evocación de la democracia plebeya ateniense surge en De la ética a la política, al hilo de la reflexión sobre el nexo entre bien privado y bien público, la "tangente ática" vinculada al ejercicio de la razón erótica en el contexto de la polis. Se trató de un "milagro político" (Domènech, 1989, 124) preservado entre el 461 y el 320 a de C., y sólo salpicado por algunos episodios de golpe de Estado antidemocrático que siempre acabaron en fracaso.

Sin embargo, el elenco de filósofos que teorizaron la cultura moral alentada en la polis ateniense se caracterizó por oponerse a la democracia entronizada tras la revolución de Efialtes. Sócrates, Platón y Aristóteles, con modulaciones diferentes como ahora veremos, rechazaron el "gobierno de los pobres". Por otro lado, los sofistas aludidos por Domènech, Trasímaco y Calicles, encarnaron la posición no sólo antidemocrática, sino antirrepublicana, opuesta a la libertad como enkrateia e independencia respecto a otro particular. Representan la extrema derecha, partidaria de un despotismo aristocrático. En defensa de la democracia plebeya, Domènech no menciona a ningún pensador de la época, aunque podía haber hecho referencia a Protágoras ${ }^{10}$. Este viejo amigo de Pericles sostuvo, frente a Sócrates y Platón,

8 Frente a esta lectura de Mosterín, véase De Francisco, A. y Aguiar, F. (1990, 169-179).

9 Contra el uso de las "laxas analogías" en ciencias sociales, Domènech (1989, 153); contra las analogías utilizadas por la teoría de la evolución social de Habermas inspirada en Piaget, Domènech, A. (1981, 28).

10 No lo menciona en este libro, pero sí en Domènech $(2004,56)$. 
que la virtud política se encontraba equitativamente repartida, de modo que era posible desarrollarla a través de la práctica, de la participación en el gobierno; no requería ningún conocimiento especializado, a diferencia del saber técnico.

Aristóteles por su parte, y aquí Domènech recurre fundamentalmente a la Política y en segundo plano a las "Éticas" (Nicomaquea y Eudemia), condena la democracia como despotismo de los pobres, de los que son incapaces de autogobierno (Domènech, 1989, 88-89, 104-105). El desarrollo de la virtud, en tanto que disposición adquirida, no es posible si no se tiene acceso a la propiedad, pues no cabe entonces ser independiente de otros. La enkrateia requiere de las circunstancias apropiadas para constituirse. Aristóteles se emplaza en una posición republicana, defiende la libertad como dominio de sí e independencia respecto a cualquier particular. Pero no considera que esa libertad pueda ser universalizada. Admite el sorteo de los cargos y la posibilidad de cambiar las preferencias y desarrollar las capacidades políticas a través de la deliberación y el ejercicio del gobierno. Pero al no aceptar la remuneración de los cargos, es decir, la institución del salario, excluye a los pobres de facto, no en teoría, pues acepta su participación en la Boulé, del gobierno de la ciudad. Sus posiciones, sugiere Domènech, se aproximan así a la representada por la Constitución de Clístenes, anterior a la establecida tras la revolución de Efialtes. Aristóteles, en suma, está cerca de la política "centrista" propugnada por Theramenes.

Del mismo modo que sucede con el planteamiento aristotélico, el socrático-platónico opta por un republicanismo no democrático, contrario al gobierno de los desposeídos. Sus posiciones se acercan también al centrismo de Theramenes y al gobierno moderado ejercido por las clases medias. Sócrates no es un demócrata pero admite el orden de la libertad republicana, por eso acepta beber la cicuta (Domènech, 1989, 88, 124) ${ }^{11}$. El modelo de Constitución más próximo a esta perspectiva es, de nuevo, el representado por Clístenes, que excluía la participación de los pobres libres al no contemplar el salario de los cargos.

La perspectiva ético-política de Sócrates y Platón, del mismo modo que la aristotélica, fundaba el buen gobierno de la ciudad en la coincidencia entre virtud privada y bien público. Pero esta fundamentación de la justicia en la tangente ática -olvidada con el triunfo de la moderna "razón inerte", poseía un perfil clasista. En ningún caso aquellos autores, ni en general el pensamiento antiguo, llegaba a plantear la cuestión de las condiciones materiales y sociales de la justicia. Ni el asunto de la coordinación justa de las actividades productivas y reproductivas, ni el problema conectado de la "desigualdad, la explotación y la opresión estructurales" (Domènech, 1989, 88). Por eso estos filósofos ignoraban las aspiraciones de los libres pobres que conformaban la mayoría de la población ateniense. No obstante, Aristóteles tenía una percepción mucho más realista de la polis que Sócrates y Platón. Sin el acceso a la propiedad, el pobre libre carecía de autarquía, estaba condenado a depender de otros, y por tanto no podía convertirse en un enkratés. Este realismo aristotélico, atento a las circunstancias que hacen posible la adquisición de la virtud, contrasta con el intelectualismo socrático-platónico.

11 Domènech parece disentir aquí de la interpretación de Rosenberg (2006, 91-92), que ve en Sócrates no sólo un antidemócrata sino un inspirador intelectual del golpe de Estado oligárquico, dado por Critias en el 404; estaría entonces más cerca de la derecha aristocratizante. 
Los que sí rompían tanto con la tangente ática como con la propia razón erótica eran los sofistas Calicles y Trasímaco, cuyas posiciones, según Domènech, fueron reactivadas por Carneades (s. II a de C.), cabeza de la Academia durante el periodo helenístico (Domènech, 1989, 123-131). Estos autores descalificaban tanto a la república de clases medias, a lo Theramenes, como a la democracia de los desposeídos. Defendían en cambio una tiranía oligárquica. Esta extrema derecha, asociada a los círculos aristocráticos atenienses, era relativista en el ámbito moral y epistémico, compartiendo una antropología naturalista y jerárquica. Los individuos nacen fuertes (ricos, nobles) o débiles (pobres), con preferencias e intereses inmodificables. La ley de la physis establecía el predominio de los fuertes sobre los débiles, pero la república, incluso en su versión no democrática, trastocaba este orden natural, instaurando el gobierno de los menos dotados. La justicia funcionaba entonces como un invento de los inferiores para subvertir el derecho de los superiores.

El menú de posibilidades que conformaba la cultura moral del mundo clásico, evocado en De la ética a la política, aparece guardando claras homologías con el pensamiento moderno. Este se caracteriza por la ausencia de la razón erótica; se trata por tanto de paisajes intelectuales distintos; las semejanzas y filiaciones sólo son posibles a partir de esta diferencia fundamental. Toda tentativa moderna de reactivar la virtud republicana, recalca Domènech, se efectúa desde aquella ausencia.

En este sentido, aunque De la ética a la política es sin duda uno los textos españoles pioneros en el debate acerca del republicanismo, su espacio de discusión no es todavía este. La controversia del republicanismo, donde se emplazará claramente El eclipse de la fraternidad (2004), no ocupaba el centro de atención del universo filosófico español en la década de los ochenta; en esa época el espacio de la filosofía académica se encontraba aún escasamente fragmentado y especializado, de modo que los problemas de teoría moral y política quedaban englobados en un marco más general. Se trataba de la controversia acerca de la razón moderna y su crisis. Lo que se dirimía era el contraste entre el sobredesarrollo de la racionalidad tecnocientífica y el subdesarrollo de la racionalidad práctica, de orden político-moral (Peñalver, 1986, 62-63; Abellán, 2005, 286-87; Vázquez, 2009, 256). Aquí se emplazaba la escisión entre "razón erótica" y "razón inerte", argumento central del primer libro de Domènech. En esas coordenadas fue recibido dentro de la comunidad filosófica española, como revela la obra más significativa de ese momento, Desde la perplejidad (1990).

Domènech por su parte, apenas alude directamente a sus colegas españoles, pero a través de las homologías que encuentra entre filósofos antiguos y modernos, en su peculiar recepción de la filosofía griega, toma posición dentro de la controversia. Sus preferencias, como se verá, son la resultante de una combinación entre su propio habitus filosófico y la gama de opciones que conformaba el campo filosófico del momento. Nos centraremos en dos cadenas de homologías histórico-filosóficas. Por una parte la constituida por la serie Calicles/Trasímaco-Nietzsche-postmodernismo; por otra parte la serie conformada por Sócrates/Platón/Aristóteles-Hegel-Arendt-Habermas. A través de la primera se toma distancia, a la vez filosófica y política, de lo que para Domènech representa el prototipo del filósofo neonietzscheano, antiilustrado, afrancesado, relativista y anarconeoliberal (o criptofascista). A través de la segunda tiene lugar un desmarque respecto a la figura del 
filósofo "puro", académico, idealista e intelectualista, fascinado por las construcciones especulativas, y ajeno a las investigaciones empíricas procedentes de las ciencias sociales.

En la esfera moral y epistemológica, esta ideología antiilustrada del derecho del más fuerte, defiende un crudo relativismo, donde no hay lugar para la universalidad y la objetividad. Descalifica la razón y la ciencia, pero también la cooperación y el altruismo, presentándolas como máscaras que encubren el imperio del interés y el afán de dominio. Históricamente alienta los movimientos de reacción antidemocrática, "hoy, como en el fin de siècle, como en la Roma del siglo II a. n. e., como en la Atenas del siglo IV a. n. e." (Domènech, 1989, 126). Justifica una visión aristocratizante y jerárquica de la sociedad, que estaría regida por la ley selvática del más fuerte. Menosprecia por ello el poder nivelador de lo público y del Estado, mostrándose con maneras "libertarias" y anticonvencionales. En el plano político esta ideología se vincula tanto con el fascismo como con el neoliberalismo ${ }^{12}$. En las ciencias sociales, aunque este argumento lo desarrolla Domènech, en intervenciones de fecha posterior, esta onda se difundirá a través de la moda académica del postmodernismo ${ }^{13}$, una suerte de "nihilismo de cátedra" empeñado en negar toda pretensión de cientificidad a las disciplinas sociales (López Arnal, 2005, 288-289 y Domènech, 1997, 14-15). El "construccionismo social" a lo Latour, la onda de los "estudios culturales" y la "descontrucción" son algunas de las manifestaciones de esta tendencia. En De la ética a la política, el representante moderno de esta ideología es Nietzsche.

Inscrito dentro del debate sobre la crisis de la razón en la modernidad, este cuestionamiento de Nietzsche va dirigido también contra sus herederos. Cuando se publicó De la ética a la política (1989), la moda neonietzscheana, impulsada en España por autores como Eugenio Trías y Fernando Savater, plasmada en las páginas de los Cuadernos de la Gaya Ciencia (1975-1977) y difundida a través de instituciones como el Col.legi de Filosofía en Barcelona o la Facultad de Filosofía de Zorroaga, se encontraba en franco reflujo (Vázquez, 2014). Su relevo había pasado a la moda postmoderna, que tenía otros valedores y otras referencias. Pero cuando Domènech, casi diez años antes, había emprendido la elaboración de su tesis doctoral, a comienzos de los ochenta, el neonietzscheanismo afrancesado todavía estaba en boga. De hecho, el grupo de los jóvenes que abanderó lo que en España fue conocido como "filosofía lúdica", se hizo visible, entre otras cosas, polemizando con el marxismo de Sacristán (Vázquez, 2014, 38). Resulta difícil no pensar en este colectivo cuando Domènech se refiere a la "apología sofista" (un libro de Fernando Savater, publicado en 1973, se titulaba precisamente Apología del sofista), cuando alude a una jeunesse dorée "libertaria" (los nietzscheanos españoles habían encarnado una suerte de bohemia dorada en versión ácrata; Vázquez, 2014, 92-100) o al citar el chiste de Lukàcs ("cuando Nietzsche se pone de moda, hay que echarse a temblar"; Domènech, 1989, 131) ${ }^{14}$.

12 Sobre la defensa de la propiedad y el "Estado mínimo", Domènech (1989, 126). Esta conexión del nietzscheanismo con el fascismo y el neoliberalismo está más desarrollada en El eclipse de la fraternidad, en un futuro artículo la examinaremos con detalle.

13 Un desenmascaramiento de las falacias inherentes a la ideología relativista del postmodernismo en ciencias sociales, puede encontrarse en Domènech (2005).

14 Domènech toma distancia no obstante de lo que considera una "grosera crítica" de Lukács al nietzscheanismo en El asalto a la razón. 
Frente al irracionalismo y relativismo nietzscheanos, De la ética a la política defiende el legado emancipatorio de un Marx republicano, heredero de la "razón erótica" y del ethos democrático erigidos en el mundo clásico, sustentado en el conocimiento empírico riguroso procedente de las ciencias sociales (Domènech, 1989, 330-335; Domènech, 1991).

Pues bien, esta escisión idealista entre la esfera cívica de la política y la esfera económica, presente en Sócrates, Platón y Aristóteles, persiste más allá del final de la "tangente ática", en la separación entre sociedad civil y sociedad política consagrada por Hegel (Domènech, 1989, 142 y 248-250). Esta dualidad está también presente en la dicotomía de Hannah Arendt, escindiendo abstractamente los universos de la reproducción ("labor") y la producción ("trabajo") respecto a la esfera política (“acción”) (Domènech, 1989, 365). En El eclipse de la fraternidad, Domènech se ocupará con más detalle de dilucidar las falacias que se derivan de estos distingos a la hora de comprender la democracia antigua. En De la ética a la política lo que se señala es la presencia de estos compartimentos categoriales de Hegel y de Arendt en la dicotomía estipulada por Habermas entre "trabajo" y "comunicación" o entre "sistema" y "mundo de la vida" (Domènech, 1989, 365).

No es posible examinar aquí con detenimiento la lectura de Habermas por Domènech. Este conocía muy bien la obra del pensador alemán. En 1981 se publicó su traducción de la tesis doctoral de Habermas, Historia y crítica de la opinión pública, editada originalmente en 1962. En el prólogo a esta versión española, Domènech adelantaba algunas de las consideraciones recogidas después en De la ética a la política. Lo que más pondera en esa opera prima de Habermas es su "solidez científica" y su "sensibilidad histórica" (Domènech, 1981, 17-18). Es precisamente la vertiente científico social de los estudios realizados en la tradición de la Escuela de Frankfurt, lo que Domènech aprecia más en este colectivo intelectual. Por eso juzga muy favorablemente la aportación de Franz L. Neumann en Behemoth (1942) (Domènech, 1981, 16-17). Sin embargo rechaza de plano la dimensión filosófica y especulativa de los frankfurtianos, patente en Adorno y Horkheimer, y cuya expresión más "grotesca" la ofrece la Dialéctica del iluminismo (1944) (Domènech, 1981, 17).

Estos esquemas de apreciación, muy arraigados en las disposiciones intelectuales de Domènech y en su modo de hibridar la filosofía con la indagación empírica, se proyectan también en su valoración de Habermas. Su obra de juventud, o más específicamente la que Domènech traduce y prologa, se mantiene muy apegada al conocimiento empírico (histórico, jurídico, sociológico), pese a la escasa formación económica de su autor (Domènech, 1981, 24). El problema es que, a medida que Habermas ha ido entrando en su madurez conceptual, se ha alejado de ese "estilo intelectual". Su desplazamiento hacia la especulación filosófica, su incorporación ecléctica de hipótesis teóricas de procedencia muy dispar y su deriva hacia la construcción de ficciones neotrascendentales, lo ha convertido en un filósofo prototípicamente académico (Domènech, 1981, 27-29) ${ }^{15}$. En ese marco se inscriben las artificiosas distinciones habermasianas entre tipos de racionalidad y en particular su diferenciación categorial entre trabajo e interacción comunicativa. La crítica de Habermas al argumento utilitarista, según el cual no es posible una elección social racional, resulta atinada. Pero

15 "A diferencia de Rawls, se trata de un filósofo [Habermas] bastante alejado del trabajo cotidiano de los científicos sociales" (Domènech, 1989, 362). 
su separación entre el mundo económico del trabajo, donde rige la razón instrumental, y el mundo político de la comunicación, impide la moralización de la vida económica. Sólo remodelando la esfera del trabajo, que no puede estar reglada exclusivamente por la lógica de preferencias e intereses considerados como inmodificables, puede democratizarse la esfera política (Domènech, 1989, 365-366). En esta crítica se entiende el arraigo de la futura lucha emprendida por Domènech para institucionalizar la renta básica, verdadero equivalente del salario por los cargos establecido en la Atenas de Efialtes.

Dada la extraordinaria importancia de Habermas en el campo filosófico español de ese momento $^{16}$, las críticas de Domènech no podían caer en saco roto. Precisamente era en la órbita de lo que se ha denominado "nódulo de Aranguren-Muguerza", y no secundariamente en el Instituto de Filosofía del CSIC, donde la obra de Habermas estaba teniendo entonces una recepción más entusiasta. En su prólogo a la Historia y crítica de la opinión pública, Domènech mencionaba la alusión irónica formulada por Javier Muguerza a propósito de la "comunidad ideal de comunicación" evocada por Habermas. Pero Domènech recordaba que los mismos tics tendentes a construir modelos normativos abstractos o neotrascendentales presentes en el alemán, podían encontrarse en el autor de La razón sin esperanza (Domènech, 1981, 32). Muguerza recogió el desafío en Desde la perplejidad (1990). El libro consiste en buena medida en un diálogo que tiene como trasfondo las propuestas habermasianas. Discute con distintos filósofos españoles autores de ensayos más o menos recientes referidos al problema de la crisis de la racionalidad. Aunque Muguerza menciona esporádicamente a Domènech (Muguerza, 1990, 15, 191, 208, 216, 347, 663) no polemiza directamente con él; lo hace con Gerard Vilar, autor del libro Raó i marxisme. Materials per a una história del racionalisme (1979), al que considera como representante de la escuela de Manuel Sacristán (Muguerza, 1990, 216). Pero en el curso de su crítica, donde se le reprocha a Vilar la identificación de la racionalidad emancipatoria con una mera variante de la razón instrumental ("razón praxeológica") (Muguerza, 1990, 232), el autor del libro vuelve a reproducir, citando a Arendt, la dicotomía habermasiana entre trabajo e interacción (Muguerza, 1990, 234-235, 252). Muguerza no sólo la da por sentada, sino que la aplica retrospectivamente a la cultura griega. Diferencia entre una historiografía marxista -fundamentalmente se refiere a Benjamin Farrington, que explica el despuntar del lógos a partir del progreso de las técnicas artesanales en el Asia menor del siglo VI a. de C., y una historiografía más centrada en el discurso, que atribuye la conquista del lógos a los avances en el dominio de las artes del lenguaje dentro de la polis (Muguerza, 1990, 238).

El cuestionamiento de esa separación como un argumento crucial para universalizar la libertad republicana, llevándola de la esfera puramente política al mundo civil, al ámbito de la producción (empresa) y de la reproducción (familia), será el hilo conductor de El eclipse de la fraternidad. En ese caso la recepción de la democracia ateniense por Domènech adoptará una nueva modulación y un nuevo estilo, enfatizando entonces la institución del salario y pasando de la teoría de juegos a la historia social. Pero ese libro aparece ya en un nuevo escenario del debate filosófico español e internacional. A su análisis dedicaremos un futuro trabajo.

16 “en un momento en que la 'moda Habermas' parece estar irrumpiendo con fuerza en los países de habla hispana" (Domènech, 1981, 13). 


\section{Referencias}

Abellán, J. L. (2005): Ortega y Gasset y los orígenes de la Transición Democrática. Madrid: Espasa, pp. 286-87.

De Francisco, A. y Aguiar, F. (1990): "La recuperación analítica de la virtud clásica", Isegoría. Revista de Filosofía Moral y Política, 2, pp. 169-179.

Domènech, A. (1981): "Prólogo a la edición castellana: el diagnóstico de Jürgen Habermas, veinte años después", en J. Habermas: Historia y crítica de la opinión pública. México: Ediciones Gustavo Gili, pp. 11-35.

Domènech, A. (1988): “Introducción. Elster y las limitaciones de la racionalidad", en J. Elster: Domar la suerte. Barcelona: Paidós/ I.C.E.-U.A.B., pp. 9-49.

Domènech, A. (1989): De la ética a la política. De la razón erótica a la razón inerte. Barcelona: Crítica.

Domènech, A. (1991): “Summum ius summa iniuria" (De Marx al éthos antiguo y más allá)", en C. Thiebaut (ed.): La herencia ética de la Ilustración. Barcelona: Crítica, pp. 175-197.

Domènech, A. (1993): “...Y fraternidad”. Isegoría. Revista de Filosofía Moral y Política, 7, pp. 49-78.

Domènech, A. (1995): "Individualismo ético e identidad personal", en R. Rodríguez Aramayo, J. Muguerza y A. Valdecantos (comps.): El individuo y la historia. Antinomias de la herencia moderna. Barcelona: Paidós, pp. 29-42.

Domènech, A. (1997): "Prólogo" a J. R. Searle: La construcción de la realidad social. Barcelona: Paidós, pp. 11-15.

Domènech, A. (1998): "Ocho desiderata metodológicos de las teorías sociales normativas" Isegoría. Revista de Filosofía Moral y Política, 18, pp. 115-141.

Domènech, A. (2004): El eclipse de la fraternidad. Una revisión republicana de la tradición socialista. Barcelona: Crítica.

Domènech, A. (2005): "El eterno retorno de Calicles. (Sobre filosofía, relativismo y ciencias sociales)", en A. Estany (ed.): Filosofía de las ciencias naturales, sociales y matemáticas. Madrid: Trotta y CSIC, pp. 293-322.

Domènech, A. (2009): "Democracia burguesa": nota sobre la génesis del oxímoron y la necedad del regalo", Viento Sur, 100, pp. 95-100.

Hansen, M. H. (1991): The Athenian Democracy in the Age of Demosthenes. Oxford: Blackwell.

López Arnal, S. (2005): "Entrevista político-filosófica a Antoni Domènech", en M. J. Bertomeu, A. Domènech y A. De Francisco (comps): Republicanismo y democracia. Madrid: Miño y Dávila.

Manin, B. (2015): Los principios del gobierno representativo. Madrid: Alianza.

Mate, R. (2012): "La función de la filosofía política. El 'Seminario Filosofía Política de Quesada', modelo del Instituto de Filosofía”, en A. García Santesmases (coord.): La filosofía política hoy. Homenaje a Fernando Quesada. Madrid: UNED.

Moreno Pestaña, J.L. (2015): "Jacobo Muñoz como marxista", en G. Cano, E. Maura y E. Moya (eds.): Constelaciones intempestivas. En torno a Jacobo Muñoz. Madrid: Biblioteca Nueva, pp. 39-76.

Mosterín, J. (1989): “Prólogo” a Domènech (1989, 15-16). 
Muguerza, J. (1990): Desde la perplejidad. Ensayos sobre la ética, la razón y el diálogo. México: FCE.

Passeron, J. C. (1991): Le raisonnement sociologique. Un espace non poppérien de l'argumentation. París: Albin Michel.

Peñalver, M. (1986): “La corporeidad de la razón: la crisis de la razón espiritualista y el fin de los dualismos" en M. Foucault et Al.: La Crisis de la Razón. Murcia: Universidad de Murcia, pp. 62-63.

Rosenberg, A. (2006): Democracia y lucha de clases en la Antigüedad. Barcelona: El Viejo Topo.

Staveley, E. (1972): Greek and Roman Voting. Ithaca: Cornell U. P.

Vázquez, F. (2009): La filosofía española: herederos y pretendientes. Una lectura sociológica (1963-1990): Madrid: Abada.

Vázquez, F. (2014): Hijos de Dionisos. Sociogénesis de una vanguardia nietzscheana (19681985). Madrid: Biblioteca Nueva. 